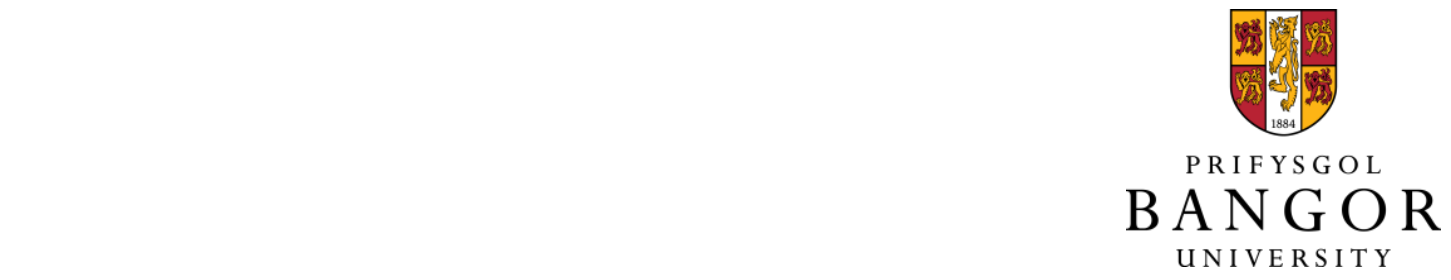

Building the Bond: Predictors of the Alliance in Neurorehabilitation.

Rowlands, Leanne; Coetzer, Rudi; Turnbull, Oliver

\title{
NeuroRehabilitation
}

DOI:

10.3233/nre-193005

Published: 21/05/2020

Peer reviewed version

Cyswllt i'r cyhoeddiad / Link to publication

Dyfyniad o'r fersiwn a gyhoeddwyd / Citation for published version (APA):

Rowlands, L., Coetzer, R., \& Turnbull, O. (2020). Building the Bond: Predictors of the Alliance in Neurorehabilitation. NeuroRehabilitation, 46(3), 271-285. https://doi.org/10.3233/nre-193005

\footnotetext{
Hawliau Cyffredinol / General rights

Copyright and moral rights for the publications made accessible in the public portal are retained by the authors and/or other copyright owners and it is a condition of accessing publications that users recognise and abide by the legal requirements associated with these rights.

- Users may download and print one copy of any publication from the public portal for the purpose of private study or research.

- You may not further distribute the material or use it for any profit-making activity or commercial gain

- You may freely distribute the URL identifying the publication in the public portal ?
}

Take down policy

If you believe that this document breaches copyright please contact us providing details, and we will remove access to the work immediately and investigate your claim. 
RUNNING HEAD: Predictors of the Alliance

\section{Building the Bond: Predictors of the Alliance in Neurorehabilitation}

Leanne Rowlands $^{12}$, Rudi Coetzer ${ }^{12}, \&$ Oliver H. Turnbull ${ }^{1}$

School of Psychology, Bangor University, Bangor, U.K. ${ }^{1}$

The North Wales Brain Injury Service, Betsi Cadwaladr University Health Board, Colwyn

$$
\text { Bay, U.K. }{ }^{2}
$$

Corresponding Author: Leanne Rowlands

leanne.rowlands@bangor.ac.uk

https://orcid.org/0000-0003-1130-5072

Word Count: 6480 
RUNNING HEAD: Predictors of the Alliance

\begin{abstract}
Neurorehabilitation services are often delivered through group psycho-education programmes. However, little is known about the therapeutic process at work during such sessions. The present study is the first to gain insight into the therapeutic alliance, during a seven session group programme. In addition, cognitive, emotional, and demographic predictors of the alliance, and participants' feelings towards their group members, were investigated, together with predictors of patient engagement. Forty-five participants with an acquired brain injury completed a series of questionnaires, and neuropsychological assessment, following group psycho-education. The group Facilitator completed a parallel therapeutic alliance questionnaire, and rated participants' engagement. Results demonstrated that a strong alliance can be formed in seven group sessions. Notably, no demographic or cognitive factors appear to pose a barrier to developing a therapeutic alliance, nor to group attraction. High levels of depression, however, may be a challenge, and clinicians may need to tailor their clinical skills to ensure a good therapeutic relationship with such patients. To promote engagement, clinicians may also need to provide additional support to patients with lower levels of education, working memory, and episodic memory impairment.
\end{abstract}

Keywords: Therapeutic alliance, working alliance, cognitive predictors, neurorehabilitation, group psycho-education, group interventions, acquired brain injury 
RUNNING HEAD: Predictors of the Alliance

Acquired brain injury (ABI) is a leading cause of disability worldwide (WHO, 2002012), with survivors experiencing a range of complex cognitive and psycho-social changes that can last a lifetime (Draper, Ponsford \& Schönberger, 2007; Ponsford, Draper, \& Schönberger, 2008). Post-injury impairments often represent a dramatic change in functioning (Colantonio, Ratcliff, Chase, Kelsey, et al., 2004; Ponsford et al., 2008), highlighting the importance of neurorehabilitation services in adjustment to the long-term consequences (Coetzer, 2008). Indeed, the chronic nature of impairment is acknowledged by the National Service for Long Term Conditions (Coetzer, Roberts, Turnbull, \& Vaughan, 2018; Department of Health, 2005). Successful rehabilitation inevitably depends on the multi-disciplinary professionals within services, with whom survivors interact (Bright, Kayes, Worrall, \& McPherson, 2015; Stagg, Douglas, \& Iacono, 2019). The collaborative nature of the client-therapist relationship, more commonly described as the therapeutic or working alliance, appears to act as a vehicle to promote positive rehabilitation outcomes (Stagg et al., 2019). Within the literature on ABI, it is poorly understood how specific features of the population might pose unique challenges to developing a strong alliance (Stagg et al., 2019).

The therapeutic alliance (TA) is a term describing the relational processes which unfold during clinical interactions, and its roots are well-established in the psychotherapy literature (Horvath \& Luborsky, 1993; Horvath \& Symonds, 1991). Bordin (1979) provides the most influential theoretical framework to follow, consisting of three underlying dimensions, which are important for the TA. These are: 1) the client and therapist agreement on the tasks to be completed as part of therapy; 2) agreement on the goals and expected outcomes; and 3) the interpersonal and emotional bond between client and therapist (Bordin, 1979). Within psychotherapy, the TA has been shown to be a reliable and moderate predictor of outcome (Hovarth \& Symonds, 1991; Martin, Garske, \& Davis, 2000, for meta-analyses), 
RUNNING HEAD: Predictors of the Alliance

the current literature in the field of neurorehabilitation provides only limited insight into this issue.

\section{The therapeutic alliance in brain injury rehabilitation}

More recently, the TA has been identified as having an enhancing effect on outcomes across rehabilitation and medical contexts (Hall, Ferreira, Maher, Latimer, \& Ferreira, 2010, for a review): For example, improving symptoms in multiple sclerosis (Rosti-Otajärvi, Mäntynen, Koivisto, Huhtala, \& Hämäläinen, 2014), a range of outcomes in the physical rehabilitation of cardiac and musculoskeletal conditions (Hall et al., 2010), and in the treatment of chronic pain (Ferreira, Ferreira, Maher, Refshauge, Latimer, \& Adams, 2013). In stroke rehabilitation, some patients perceive the quality of the client-therapist partnership to be of primary importance, above that of the therapy's content or duration (Peris, Taylor, \& Shields, 2012). Despite only limited research into the role of the TA in ABI rehabilitation, the emerging idea is that it shapes outcomes, and is influenced by several factors present in the rehabilitation environment (Stagg et al., 2019, for a review).

The majority of empirical investigations of the role of the TA in rehabilitation outcomes have focused on vocational issues (work, work prospects, school), and have demonstrated positive associations (Evans, Sherer, Nakase-Richardson, Mani, \& Irby, 2008; Klonoff, Lamb, \& Henderson, 2001; Lustig, Strauser, Weems, Donnell, \& Smith, 2003; Schönberger, Humle, Zeeman, \& Teasdale, 2006a; Stagg et al., 2019, for a review). Important clinical outcomes include improved independence and social interactions, and reduced communication difficulties and somatic problems (on the European Brain Injury Questionnaire) (Schönberger, Humle, \& Teasdale, 2006b).

Finally, it has been demonstrated that the TA promotes patient compliance with a holistic rehabilitation programme, through its impact on self-awareness (Schönberger, Humle, \& Teasdale, 2006c). That is, the TA alliance enhances patient awareness, and those 
who are aware of their difficulties comply and engage in rehabilitation (Schönberger et al., 2006c). Patient engagement with the rehabilitation process is thought to play an important role in its success and adherence (Bright, Kayes, Worrall, \& McPherson, 2015, for a review; Lenze, Munin, Quear, Dew, et al., 2004). The patient-therapist relationship is a potential mechanism to enhance engagement, with the majority of evidence from qualitative accounts (Bishop, Kayes, \& McPherson, 2019; Bright, Kayes, Cummins, Worrall, \& McPherson, 2017; Lawton, Haddock, Conroy, \& Sage, 2016). The direct role of the TA on engagement, however, remains unclear.

\section{Predictors of the therapeutic alliance}

If the TA is considered a crucial component of rehabilitation by patients and professionals (Lawton et al., 2016), careful attention needs to be paid to the factors which might impede (or facilitate) the development of this process. This is especially relevant in the context of ABI, where the nature of impairment may place unique demands on the TA. For example, a number of interesting interpersonal factors have been identified through qualitative work, including a genuine bond within the therapeutic rapport, and professional collaboration (Bishop, Kayes, \& McPherson, 2019; Lawton et al., 2016). Additional insights from qualitative research identify a range of cognitive consequences as the most frequently reported challenges in developing an alliance, followed by emotional factors, and behavioural disinhibition (Judd \& Wilson, 2005).

Quantitative research provides modest insight into the factors which promote positive perceptions of the TA, for both patients and professionals (Stagg et al., 2019). For example, studies have demonstrated that younger patient age (Schönberger et al., 2006c) and greater years in education (Sherer, Evans, Leverenz, Stouter, Irby, et al., 2007) positively influenced the strength of the alliance. In terms of injury-specific factors, the influence of cognitive factors has been reported to be weak in nature, and differentially associated to therapist and 
client perceptions (Schönberger, Humle, \& Teasdale, 2007). For instance, poor attentional impairment may influence the strength of the alliance negatively, whereas poorer

performance on a memory task may have a positive influence, albeit weakly (Schönberger et al., 2007). The authors reported that, out of the several higher cognitive functions explored, verbal fluency and IQ (Information sub-test of the Wechsler Adult Intelligence Scale) was found to be positively related to aspects of the TA. It is noteworthy, however, that the findings of these correlational analyses were not subject to an alpha adjustment, and should be interpreted with caution.

Most of the work investigating the TA in neurorehabilitation has focused on holistic (and intense) programmes, and are correlational in nature (Stagg et al., 2019). However, in a recent study Zelencich and colleagues (2019) aimed to address these gaps by using regression analyses to explore the predictors of the TA in the context of cognitive behaviour therapy (CBT) for people with brain injury. In contrast to previous work (Schönberger et al., 2006c Sherer, Evans, Leverenz, Stouter, et al., 2007) no demographic factors were found to have an influence, however greater time since injury was predictive of a stronger TA. Interestingly, no measure of memory or executive function was predictive of the strength of the therapeutic relationship (Zelencich, Kazantzis, Wong, McKenzie, et al., 2019). This robust empirical finding is suggestive that an ABI, and related cognitive impairment, does not necessarily pose a barrier to developing an effective TA, at least in the context of CBT.

\section{Emotional predictors of the therapeutic alliance}

One aspect of brain injury that may pose a barrier to the TA, but has not received much attention in the literature, are the emotional consequences. It is widely acknowledged that a brain injury often results in a range of emotional difficulties, most commonly depression and anxiety (Hiott \& Labbate, 2002; Jorge, Robinson, Moser, Tateno, et al., 2004; Kreutzer, Seel, \& Gourley, 2001). Such difficulties can impact upon many aspects of life 
RUNNING HEAD: Predictors of the Alliance

(Ponsford et al., 2008), are a significant source of care-giver burden (Ergh, Rapport, Coleman, \& Hanks, 2002), and compromise socio-emotional functioning (Ownsworth \& Fleming, 2005). It seems, therefore, possible that emotional factors may also play a role in rehabilitation engagement and the therapeutic relationship, especially given that the establishment of an emotional bond is a core component of the TA (Bordin, 1979). Additionally, emotional factors such as depression are known to effect motivation (Smith, 2013), which may in turn influence task and goal agreement (additional dimensions of the TA). Indeed, qualitative evidence points to the limiting effect of emotional consequences on developing a strong patient-therapist bond (Judd \& Wilson, 2005). Only two studies have directly explored the influence of emotional distress (Evans et al., 2008; Sherer et al., 2007), with one demonstrating a significant association between higher alliance ratings and lower levels of depression (Evans et al., 2008). The other, however, found no significant role (Sherer et al., 2007). Both studies were limited, in that all measures were collected within the first two weeks of therapy, when sufficient time had not passed to develop the alliance (Schönberger et al., 2006c)

\section{Therapeutic alliance across rehabilitation settings}

Another issue which has not been previously investigated is how the TA, and factors affecting it, might play out in various rehabilitation settings. As previously mentioned, the existing studies have predominantly focused on holistic post-acute services, which are typically intense in nature (e.g. a number of sessions a week for several months). Intensive rehabilitation is not available for everyone, and service provision remains under-developed in many locations (Krug \& Cieza, 2019). Many community services, therefore, seek out costeffective theoretically driven models to rehabilitate their patients (Coetzer, et al., 2018). One such component of community services includes group psycho-education, to improve ABI consequences and understanding of injury (Backhaus, Ibarra, Klyce, Trexler, \& Malec, 2010; 
RUNNING HEAD: Predictors of the Alliance

Coetzer, 2008; Couchman, McMahon, Kelly, \& Ponsford, 2014). Such programmes are common across services (Tyerman \& Hucker, 2006), but to our knowledge there has been no previous investigation of the TA (and influencing factors) with the facilitators of group psycho-education programmes.

According to Bordin (1979) the TA is relevant across all settings which involve a process of change, and that each new environment may bring to light factors which could shape its strength. Given the role of the alliance in rehabilitation outcomes (Stagg et al., 2019), and the benefit of group psycho-education programmes within services, it is important to develop an understanding of influencing factors within this context. Additionally, one of the biggest values of group programmes for patients is the quality of the group interaction, and the informal learning which stems from it (Anson \& Ponsford, 2006; Lundqvist, Linnros, Orlenius, \& Samuelsson, 2010). A member's feelings towards their group contributes to a number of important processes (Yalom \& Rand, 1966), including outcome (Crowe \& Grenyer, 2008; Marziali, Munroe-Blum, \& McCleary, 1997). Factors affecting the strength of the group attitude may, therefore, be additional components worthy of investigation.

The present study, to our knowledge, is the first to investigate facilitator and patient perceptions of the strength of the alliance, from a short-term group psycho-education programme. Uniquely, it also aimed to investigate how emotional factors, as well as cognitive and demographic factors ${ }^{1}$, might influence the formation of both the therapeutic relationship and the group attitude. Finally, the present study aimed to investigate whether the factors of TA, group attitude, and emotional, cognitive, and demographic variables (age and education) were predictive of patient engagement within the group programme. Such data would allow clinicians to identify which patients may be vulnerable to experiencing

\footnotetext{
${ }^{1}$ Time since injury was not considered due to the highly skewed and bimodal nature of this variable within the sample.
} 
RUNNING HEAD: Predictors of the Alliance

challenges in forming a strong TA or poor programme engagement, allowing them to tailor their clinical and interpersonal skills accordingly (Bishop et al., 2019).

\section{Methods}

\section{Participants}

Forty-five participants with an ABI were included in the present study. Each had successfully completed of a seven-week group psycho-education programme (The Brain Injury Solutions and Emotions Programme, BISEP) at a community outpatient rehabilitation unit, the North Wales Brain Injury Service, Betsi Cadwaladr University Health Board (NWBIS, BCUHB). The sample consisted of 11 women and 34 men, ranging from 26 to 86 years old $(M=52, S D=12)$, with mixed pathology, reflective of the rehabilitation environment. It included 21 people who had suffered a cerebrovascular accident (CVA), 17 who had suffered a traumatic brain injury (TBI), four who had an ABI following encephalitis, one following hypoxia during cardiac arrest, one following tumour recession, and one from the effects of radiation therapy. Participants ranged from nine-months following injury to 32 years $(M=5$ years, $S D=8$ years, $M D N=2$ years $)$. Participants were referred to BISEP by a NWBIS clinician, and consisted of those with confirmed ABI (as per NWBIS criteria, Coetzer, Vaughan, Roberts, \& Rafal, 2003), duration of at least nine months or greater since injury, and sufficient language ability to benefit from a language-based intervention. Exclusion criteria were inability to give informed consent, and the presence of a neurodegenerative condition (one participant excluded based on this criterion), learning disability, or psychiatric disorder in need of acute care.

\section{Measures}

\section{Therapeutic Alliance}

The present study used the shortened version of the Working Alliance Inventory (WAI-S) (Tracey \& Kokotovic, 1989), originally developed by Horvath and Greenberg 
(1989). This measure is based upon Bordin's pantheoretical model (1979) of TA and is widely used, including in studies on brain injury (Schönberger et al., 2006c). The measure includes parallel client and therapist versions, with reports of high reliability ( $\alpha=.95$ for therapist ratings, $\alpha=.97$ for therapist ratings) (Tracey \& Kokotovic, 1989). The WAI-S scale ranges from 12 (lowest alliance) to 84 (highest alliance), and includes 12 items which are responded to on a seven-point scale. Although this measure includes subscales capturing the three dimensions of the alliance, the aim of the present study was to investigate the overall alliance score (considered the most valid way to represent the measure, Tracey \& Kokotovic, 1989). Patient and therapist versions were administered, to capture both perceptions. These were completed by all patients, and by the programme Facilitator, immediately after the last session of BISEP, to allow sufficient time to develop the alliance over the seven session programme (Schönberger et al., 2006c). It was explained that participants and facilitator ratings would remain confidential, and data were anonymised by a research intern, prior to the analyses. If needed, participants were assisted in completing the form by a member of the NWBIS clinical team. Participants especially benefitted for an awareness of the two items on the scale that were reverse-scored.

\section{Group Attraction}

Within psychotherapy, aspects of the group dynamic (e.g. conflict and collaboration) have been shown to predict outcome within group programmes (Crowe \& Grenyer, 2008). The present study, therefore aimed to capture members' perceptions and attraction towards their group, and investigate potential barriers. To do this, the Group Attitude Scale was used (Evans \& Jarvis, 1986). The Group Attitude Scale is a 20 item measure, scored on a 9-point Likert scale, where higher scores indicate more positive attitude towards their group. It reports high validity and reliability $(\alpha=.90-.97)$, and is considered reliable within the present sample $(\alpha=.81)$. This measure was chosen as it captures members' desire to identify 
RUNNING HEAD: Predictors of the Alliance

with, and be accepted by, their group. This element, relating to other survivors, is perceived as an important component by brain injury groups (Couchman et al., 2014; Levack, Kayes, \& Fadyl, 2010; Salas, Casassus, Rowlands, Pimm, \& Flanagan, 2018).

\section{Engagement}

Patient engagement with the programme was defined as "deliberate effort and commitment" to partake in the goals and activities of the programme, demonstrated through active participation in the learning process, intervention activities, and group discussions (Lequerica \& Kortte, 2010). Similar to Schönberger et al (2006a), engagement was rated by the BISEP facilitator on a five-point scale: 1) little or no activity, 2) activity when supported, 3) active without participation, 4) active and prepared, and 5) active, independent and spontaneous input.

Emotion symptomology

To measure anxiety and depression symptomology the Hospital Anxiety and Depression Scale (HADS; Zigmond \& Snaith, 1983) was used, which includes two subscales. The HADS and has been validated in people with ABI (Dawkins, Cloherty, Gracey, \& Evans, 2006; Schönberger \& Ponsford, 2010). Participants indicate, on a 4-point scale, agreement with statements such as "I still enjoy the things I used to enjoy".

\section{Cognitive measures}

Three tasks were chosen to measure higher cognitive functions. These include: 1) Inhibition, which was measured with the Hayling sentence completion task from the Hayling and Brixton tests (Burgess \& Shallice, 1997). This reports high sensitivity (Burgess \& Shallice, 1997), and validity in a sample of brain-injured patients (Odhuba, van den Broek, \& Johns, 2005). 2) Working Memory was assessed using the Digit Span sub-task from the Wechsler Adult Intelligence Scale (WAIS IV) (Wechsler, 2008), widely used in individuals with ABI (Millis, Rosenthal, Novack, Sherer, et al., 2001). 3) Verbal Ability was measured 
RUNNING HEAD: Predictors of the Alliance

using the Letter Fluency sub-task from the Delis-Kaplan Executive Function system (DKEFS) (Delis, Kaplan, \& Kramer, 2001), which is thought to be one of the strongest predictors of cognitive control (Henry \& Crawford, 2004). Finally, memory was assessed using the Logical Memory sub-tasks from the Wechsler Memory Scale (immediate and delayed recall) (WMS-IV, Wechsler, 2009). This is an "industry standard" test of memory widely used in clinical practice and research within the context of ABI.

\section{Procedure}

The study was granted ethical approval by the School of Psychology, Bangor University (2017-16048), and BCUHB (224613). Participants were referred to BISEP by their clinician, and attended the programme in addition to their usual care at the community outpatient service. Approximately two weeks before programme commencement, participants completed the HADS and neuropsychological assessment in random order, as part of a larger research project, and had the opportunity to ask questions about the BISEP. This was done by the first author (LR) at the NWBIS, Bangor University, or patients' homes. Group members had no therapeutic contact with the programme Facilitator outside BISEP. The psychoeducation and skills-based intervention forms a seven session programme, where members meet once a week for two hours. It is run by a main facilitator (the first author, LR) and a cofacilitator (an additional member of the clinical team, which was held constant as much as possible). BISEP topics include an introductory session, and sessions on anatomy and mechanisms of injury, emotional changes, emotion regulation, memory, problem solving, and fatigue. Patients receive handouts to provide structure, and each session involves a mixture of formal learning, compensatory strategies, skill building, and group discussions. The BISEP ends with a party and certificates, which the members help to organise.

Group members and the programme facilitator completed the TA questionnaires (WAI-S) following the last session, and the facilitator rated group members on their overall 
RUNNING HEAD: Predictors of the Alliance

engagement. To encourage group members to answer honestly, they were informed that the facilitator would not see the data. A research intern anonymised data prior to analysis.

Participants completed the Group Attitude Scale independently of their group members soon after (within two-weeks) programme completion.

\section{Design and Data Analysis}

This non-experimental correlational design study used a series of robust multiple linear regressions were carried out, given the assumption of residual normality was not met. This was done using ' $\mathrm{R}$ ' software, with the additional packages 'Robustbse', 'Complmrob', and 'Stats'. Robust regressions were performed with 'MM' method (Salibián-Barrera, Aelst, \& Willems, 2008), and bootstrapped coefficients from 999 bootstrapped samples (as a form of model validation) (Babyak, 2004; Efron, 2003). A number of separate regression models were carried out, with 1) demographic predictor variables (age and education), with 2) cognitive predictors (logical memory immediate recall, delayed memory recall, working memory, verbal ability, and inhibition), and with 3) emotional predictors (anxiety and depression scores). These were entered into regression models for 1) patient TA ratings, 2) programme facilitator (therapist) alliance ratings, and 3) group attitude scores as separate outcome variables. Additionally, a number of regression analyses were carried out for the outcome variable of patient engagement, with demographic, cognitive, and emotional predictors (as above), and an additional regression for alliance as predictors (patient ratings, therapist ratings, and group attitude). Missing data for one participant on the Group Attitude Scale was omitted.

\section{Results}

The present study aimed to increase understanding of patient and Facilitator perceptions of the strength of the alliance, in a short term (seven week) psycho-education group programme, carried out at a community neurorehabilitation service (analysed under 
RUNNING HEAD: Predictors of the Alliance

“The therapeutic alliance for group psycho-education"). A second aim was to investigate demographic, emotional, and cognitive predictors of the alliance and group attitude, as a way to identify potential barriers or facilitating factors (see "Predictors of the therapeutic alliance and group attitude”). A final aim was to explore potential predictors of patient engagement with the programme (demographic, emotional, cognitive, and alliance) (see "Predictors of patient engagement"). For descriptive statistics see Table 1.

[Table 1 Here]

\section{The therapeutic alliance for group psycho-education}

Patient and Facilitator perceptions of the strength of the alliance was high overall, with a median rating of 74.50 for patients, and 69 for facilitators (from a maximum of 84). No rating was below 52 (patient ratings) and 46 (facilitator ratings). Importantly, $36 \%$ of the patients rated the alliance as 80 or above, with $16 \%$ of those as rating the alliance as the highest possible (84/84). The percentage of facilitator ratings above 80 was less high $(9 \%)$. For patient ratings, over $50 \%$ of the sample reported their perceptions of the strength of the alliance to be over 74 , and for the facilitator ratings over $50 \%$ were higher than 69 . Patient ratings of the strength of the TA were significantly higher than facilitator ratings $(Z=-2.787$, $p=.005)$. Importantly, patient and facilitator ratings were strongly correlated $(r=.71, p$ $<.001$, see Figure 1). The results indicate that a strong alliance can be achieved within the context of a short-term group rehabilitation programme.

[Put Figure 1 Here]

\section{Predictors of the therapeutic alliance and group attitude}

Patient perceptions of the alliance

Three robust regression models were carried out (for demographic, cognitive, and emotional predictors), see Table 2 for details. According to these models, demographic variables (age and education), cognitive (inhibition, working memory, verbal fluency, 
RUNNING HEAD: Predictors of the Alliance

memory 1 and 2), and emotional (anxiety and depression) predictor variables provide a very low explanation of variance of the patient TA ratings, and none significantly improve prediction.

[Table 2 Here]

\section{Therapist perceptions of the alliance}

For the Facilitator's ratings, the model containing emotional predictor variables (anxiety and depression) explained $16 \%$ of the variance, and significantly improved prediction of the Facilitator's perceptions of the strength of the TA $\left(\mathrm{R}^{2}=.16, F(2,44)=\right.$ $17.11, p<.001)$. Bootstrapped coefficients demonstrated that depression scores (HADS) were the only significant predictor within the model $(\beta=-0.83, p=.002)$, and that a unit increase in depression scores would result in a 0.83 decrease in facilitator TA ratings.

The models with demographic, and cognitive, predictor variables did not significantly improve prediction of TA compared to using the mean alone. See Table 3 for further details. The results indicate that cognitive impairment is no barrier to developing a working alliance. This important issue is addressed in the Discussion.

[Table 3 Here]

\section{Group attitude}

The regression model which explained most variance was that containing the emotional predictor variables (anxiety and depression). This model explained $14 \%$ of the variance, and significantly improved prediction of group attraction, compared to using the mean alone $\left(\mathrm{R}^{2}=.14, F(2,44)=9.48, p=.008\right)$. The results suggest that depression scores were the only significant predictor within the model $(\beta=-1.61, p=.006)$, suggesting that a unit increase in depression scores would result in a 1.61 decrease in participants' "attraction" to their group (group attitude scale). 
RUNNING HEAD: Predictors of the Alliance

No other regression model significantly improved prediction of participants' scores on the group attitude scale (demographic predictor model: $p=.249$; cognitive predictor model: $p=.340$ ). Verbal fluency was, however, a marginally significant predictor within the cognitive model $(\beta=-1.57, p=.049)$, suggesting it may play a small role (See Table 4 for details). No demographic predictors and most cognitive factors did not predict group attitude; however depression was a substantial contributor. Again, this issue is raised in the Discussion.

[Table 4 Here]

\section{Predictors of patient engagement}

Four robust regression models were carried out to investigate demographic, cognitive, emotional, and alliance predictors of patient engagement with the programme. The results demonstrated that the demographic predictor model (containing age and education) explained $14 \%$ of the variance (as rated by the facilitator), and significantly improved prediction of patient engagement $\left(\mathrm{R}^{2}=.14, F(2,44)=7.84, p=.020\right)$. Patients' years in education was the only significant predictor within the model $(\beta=0.22, p=.005)$, suggesting that a 1 year increase in education would result in a 0.22 increase in (the 5-point) engagement scores.

The regression model containing the cognitive predictors (inhibition, working memory, verbal fluency, immediate memory recall, and delayed memory recall) explained $19 \%$ of the variance, and significantly improved prediction of patient engagement $\left(\mathrm{R}^{2}=.19\right.$, $F(5,44)=13.49, p=.019)$. Working memory was a significant predictor within the model $(\beta$ $=0.18, p=.018)$, suggesting that a unit increase in working memory would again result in a substantial 0.18 increase in engagement. Interestingly, immediate memory recall was a significant positive predictor of engagement $(\beta=0.29, p=.033)$, whereas delayed recall was a significant negative predictor $(\beta=-0.26, p=.037)$. This suggests that a unit increase in 
RUNNING HEAD: Predictors of the Alliance

immediate memory recall would result in a 0.29 increase in engagement, but a unit increase in delayed memory recall would result in a 0.26 decrease in engagement.

The model containing emotional and alliance predictors did not significantly improve prediction of engagement, and had low explanation of variance (See Table 5). These results are clearly both clinically useful and complex, and are interpreted in the Discussion.

[Table 5 Here]

\section{Discussion}

\section{A strong alliance can be developed surprisingly quickly}

Importantly, these findings suggest that a strong TA can be achieved in a short-term group psycho-education programme. This conclusion stems from the observation that $50 \%$ of alliance ratings were over 74 (patient ratings) and 69 (therapist ratings). As discussed above, previous work has focused mainly on intense holistic rehabilitation (Stagg et al., 2019, for a review). This finding, in a short term group programme, is consistent with the idea that the alliance is relevant across settings involving a process of change (Bordin, 1979), especially for patient perceptions.

Previous work has suggested that the strength of alliance is dependent upon the quantity of therapeutic contact, and develops over time (Schönberger et al., 2006c). The present study's findings suggest that a strong TA can be developed over 7 short session. It may, therefore, be the quality of the therapeutic contact that is most important (Bishop et al., 2019; Lawton et al., 2016). In addition, an essential component of the therapeutic relationship is person-centredness (Bishop et al., 2019; Lawton et al., 2016), something which may have been considered difficult to achieve in a group setting. These findings suggest that this is not the case, and providing rehabilitation in a group setting is not necessarily a barrier to developing an alliance with the members. It has been suggested that this effect is to a clinician's skill in recognising variability among patients, and tailoring their approach 
RUNNING HEAD: Predictors of the Alliance

accordingly (Bishop et al., 2019; McCormack, Karlsson, Dewing, \& Lerdal, 2010). These results should be encouraging for all those who engage in short-term group rehabilitation programmes.

\section{Cognitive and demographic variables are not predictors of alliance}

Another important finding is that demographic and cognitive variables do not appear to influence the strength of the alliance (for facilitator or patient perceptions), or the patients' 'attraction' towards their group. Similar to previous studies, this finding suggests that age (Sherer et al., 2007) and education (Zelencich et al., 2019), do not pose a barrier to developing a strong therapeutic relationship with ABI survivors. This can only be seen as a positive for rehabilitation, because of the wide range of brain injury demography: young adults and the elderly, and all levels of education.

Surprisingly, no cognitive factors were identified as having an influence on patient or therapist perceptions of the TA, in contrast to qualitative accounts (Judd \& Wilson, 2005). This particular finding contributes to an emerging picture in the quantitative literature, that cognitive impairments in the ABI population do not necessarily pose a challenge in developing a therapeutic relationship (Stagg et al., 2019; Zelencich et al., 2019). Of particular relevance for this idea is a recent detailed description of the inter-personal psychotherapeutic process, which remains intact with a profoundly amnesic patient (Moore, Salas, Dockree, \& Turnbull, 2017). The Facilitator's skills in circumventing cognitive difficulties (Judd \& Wilson, 2005; Schönberger et al., 2007), and specific elements of BISEP (e.g. handouts and prompts) (Judd \& Wilson, 2005), may also play a part.

Additionally, no cognitive factor was found to play a role in participants' 'attraction' towards their group. It is important to note that this specific measure captures important elements of the group interaction, such as relating to the experiences of other group members, and a feeling of unity (Evans \& Jarvis, 1986). One may have expected cognitive difficulties 
RUNNING HEAD: Predictors of the Alliance

to negatively impact this group element, given their substantial role in social skills (Muscara, Catroppa, \& Anderson, 2008; Salas, Casassus, Rowlands, Pimm, \& Flanagan, 2018), and psycho-social outcomes (Draper, Ponsford, \& Schönberger, 2007). However, given that cognitive impairment is often a feature of a brain injury, and an element which unites the group members, participants likely did not see this as a barrier (Salas et al., 2018). The high scores on this measure indicate that participants are not only able to relate to one another, but that they also enjoyed the group experience, regardless of age, education, and cognitive abilities.

It is noteworthy that a number of qualitative factors, not investigated in the present study, might play a part in the alliance (Lawton et al., 2016 for review), and group 'attraction'. For example, the fostering of a personal connection, humour, empathy (Bishop et al., 2019), trust, and being treated as an individual (Lawton et al., 2016 for review).

Considered together, it is possible that a number of personal and professional characteristics, independent of injury-related factors, underlie these complex therapeutic processes. Again, these findings are encouraging for those who work with patients from a range of demographic backgrounds, with cognitive impairment.

\section{Depression is a significant predictor, but not in all cases}

A key finding is that depression scores negatively predicted firstly, the facilitator perceptions of the alliance, and may, therefore, be a barrier to developing a strong therapeutic relationship. This idea is consistent with previous findings (Evans et al., 2008), and qualitative evidence, which suggests that 'emotional difficulties' are often a challenge to developing an alliance (Judd \& Wilson, 2005). It is widely acknowledged that emotional distress can impact on processes important in rehabilitation (Coetzer et al., 2018), such as motivation (Siegert \& Taylor, 2004) and appraisals of impairment (Byrne, Coetzer, \& Addy, 
2017). The present study's findings extend this idea, by providing direct evidence that depression also negatively impacts the development of the TA.

What might explain this effect? Referring back to Bordin's pantheoretical framework (1979), it is possible that depression may have affected the dimensions of the TA differentially. For instance, depression may have influenced the more active components of the TA, such as agreement on tasks and goals. Notably, depression symptomology may decrease motivation and self-efficacy (Maddux \& Meier, 1995; Smith, 2013), and in turn may make participants more passive in task agreement (Gibbon, 2004; Lawton et al., 2016 for a review; Rhode, Townley-O’Neill, Trendall, Worrall, \& Cornwell, 2012). Interestingly, depression was not predictive of patients' perceptions of the alliance, possibly due to poor awareness (Prigatano, 2005), or general positive perceptions leading to high ratings within a narrow range.

A second finding on this topic is that depression also negatively predicted participants' 'attraction' towards their group. It has been long acknowledged that emotional distress can play a role in social functioning (Gainotti, 1993; Morton \& Wehman, 1995; Weddel, Oddy, \& Jenkins, 1980). Within the context of rehabilitation programmes, depression may impact upon the group dynamic in a number of ways. Firstly, high depression symptomology may lead to a negative bias (Peckham, McHugh, \& Otto, 2010; Watkins, Vache, Verney, Muller, \& Mathews, 1996), whereby participants' overall views of the group experience may be influenced by a preoccupation with instances of negative interactions. Secondly, as previously mentioned, depression may lead to poor motivation (Smith, 2013) to connect with the group. A final issue is how depression might compromise a person's sense of identity (Cruwys, Haslam, Dingle, Haslam, \& Jetten, 2014). Due to a sense of threat to the self, a person might use maladaptive strategies, such as avoidance, as a way of coping (Riley, Brennan, \& Powell, 2004). That is, they may stay on the outskirts of the group, and avoid 
RUNNING HEAD: Predictors of the Alliance

becoming actively involved in relational elements that are important for developing a strong group bond (e.g. discussions, activities, sharing their own stories). This has important clinical implications as discussed below.

\section{Education is the biggest predictor of engagement}

Within neurorehabilitation, a person's level of education has been identified as a factor which positively influences outcome (Ponsford, Draper, \& Schönberger 2008), including employment and fewer depressive symptoms (Whelan-Goodinson, Ponsford, Schönberger, \& Johnston, 2010). It is, therefore, not surprising that the findings suggest that higher levels of education are also predictive of engagement, consistent with previous research in acute inpatient rehabilitation (Ramanathan-Elion, McWhorter, Wegener, \& Bechtold, 2016).

The majority of studies of rehabilitation engagement have investigated the role of psychological variables, such as hope and denial (Ramanathan-Elion et al., 2016), but factors contributing to this process remain poorly understood. Lequerica and Kortte (2010) provide a useful model, whereby engagement is dependent upon interacting personal and environmental factors. The present study's findings suggest that the level of education may also play a part in the underlying factors, possibly through perceived self-efficacy (Lequerica $\&$ Kortte, 2010). It is, therefore, important for clinicians to actively promote engagement in group members with lower levels of education.

\section{Some cognitive abilities are important for engagement}

Another key finding is that aspects of cognition are important for engagement. Though this area of research is in its infancy, these findings are in line with previous research on participation in rehabilitation, a related and overlapping construct to engagement (Skidmore, Whyte, Holm, Becker, et al., 2010). This presumably relates to the idea that 
RUNNING HEAD: Predictors of the Alliance

cognitive impairment presents a hindrance to engaging in every-day life, and in social adjustment (Salas et al., 2018).

Of the cognitive factors explored, the present study is the first to demonstrate that good working memory significantly predicted higher levels of engagement (c.f. Skidmore et al., 2010). One can see why intact levels of this limited-capacity ability would be beneficial within the context of a group psycho-education programme, where one must follow the content, listen to the group members' accounts, take part in programme activities, all the while keeping track of the overall narrative of each session (Mcallister, Flashman, Sparling, \& Saykin, 2004, for a review). When this system becomes overloaded, participants may well disengage from the sessions, as a way to avoid a catastrophic reaction (Goldstein, 1965; Salas, 2012). The findings suggest that those with marked working memory difficulties might need additional support to maintain engagement.

A peculiar finding is related to episodic memory (Logical Memory, WAIS). The present study suggests that poorer immediate memory recall is predictive of lower engagement, but poorer delayed memory recall is predictive of higher engagement. For the former, it is likely that those who cannot remember the content as it progresses during each session may disengage. A possible explanation for the latter is that patients who are aware of delayed memory impairment may engage more during future sessions in an attempt to compensate. Previous work by Schönberger et al (2007) found that poorer memory was associated with better patient perceptions of the alliance, it's possible that this too was due to increased engagement with the therapeutic process. It is not easy to interpret these complex findings, but encouraging patients to take notes, and providing information in 'bite sized' chunks, would be practical suggestions to promote engagement.

\section{Therapeutic alliance may not predict engagement}


RUNNING HEAD: Predictors of the Alliance

The therapeutic alliance was not a predictor of engagement in the present study. However, this stands in sharp contrast to previous qualitative work, which have described the therapists as having a 'pivotal' role in encouraging patient engagement, and that the alliance might be a mechanism by which to promote participation (Bright et al., 2015; Lawton et al., 2016, for reviews). It is likely that, in a group setting, engagement is dependent on personal characteristics (e.g. education), psychological factors, and the programme itself, more so than the therapeutic relationship. Engagement is a complex phenomenon; to better understand the process it is important to use both quantitative and qualitative approaches from the same data set. This seems to be the most sensible way forwards, because at the moment these methods seem to be producing different results. In addition, future work may benefit from following more closely a model of therapeutic engagement (e.g. Lequerica \& Kortte, 2010).

\section{Future directions}

A possible limitation of the present study is that the focus upon the overall alliance prevents more detailed analysis of the three underlying dimensions, especially as these develop over multiple time points. As regards cognitive skills, a variable which may be important to consider in future studies is sustained attention (Leclercq, Deloche, \& Rousseaux, 2002). This impairment, commonly described as distractibility, might play a role in participants' engagement with rehabilitation programmes and with the therapeutic relationship (Schönberger et al., 2007). Finally, future work will benefit from investigating the importance of the alliance for the outcomes of group rehabilitation programmes.

\section{Implications for neurorehabilitation}

The present study has several implications for rehabilitation professionals, of which the most important may be that cognitive impairment following ABI does not pose a barrier to developing an alliance with their clients. The relevance of depression symptomology is also a clinically important finding, and suggests that rehabilitation professionals should 
RUNNING HEAD: Predictors of the Alliance

identify those vulnerable to poorer alliance and group connection. Facilitators can then pay extra attention to participants with high levels of depression, and provide scaffolding and encouragement to help them with tasks and activities. Additionally, clinicians may need to actively help such patients to bond with the group, by drawing them into group discussions, and help them move past maladaptive ways of coping (e.g. avoidance, as discussed above) (Riley et al., 2004). Professionals may wish to tailor their approach according to known factors contributing to engagement, especially lower levels of education, poorer working memory skills, and poorer episodic memory.

\section{Conclusion}

The findings demonstrate that a good alliance can be achieved despite short duration, demographic variation, and cognitive impairment. Some barriers to the alliance, patient engagement, and group 'attraction' have, however, been identified. The present study provides direct evidence that depression negatively influences the strength of the alliance, and participants' 'attraction' towards their group. To promote engagement, clinicians may need to provide additional support to patients with lower levels of education, working memory, and episodic memory impairment. We have suggested practical solutions which can address these challenges. Given the financial and workload advantages of short-term group interventions, these positive findings encourage the continued use of group programmes for neurorehabilitation services.

\section{Acknowledgements}

This study was supported by EU Social Fund through the Welsh Government. We would like to thank all the participants and staff at the North Wales Brain Injury Service. Our gratitude also goes to patients' friends and family, and the Welsh Ambulance Service NonEmergency Transport, for driving the participants to the psycho-education sessions. 
RUNNING HEAD: Predictors of the Alliance

\section{Disclosure Statement}

The authors have no conflict of interest to disclose

\section{References}

Anson, K., \& Ponsford, J. (2006). Evaluation of a coping skills group following traumatic brain injury. Brain Injury, 20(2), 167-178. DOI: https://doi.org/10.1080/02699050500442956

Babyak, M. A. (2004). What you see may not be what you get: a brief, nontechnical introduction to overfitting in regression-type models. Psychosomatic medicine, 66(3), 411-421.

Backhaus, S. L., Ibarra, S. L., Klyce, D., Trexler, L. E., \& Malec, J. F. (2010). Brain injury coping skills group: a preventative intervention for patients with brain injury and their caregivers. Archives of physical medicine and rehabilitation, 91(6), 840-848. DOI: https://doi.org/10.1016/j.apmr.2010.03.015

Bishop, M., Kayes, N., \& McPherson, K. (2019). Understanding the therapeutic alliance in stroke rehabilitation. Disability and rehabilitation, 1-10. DOI:

https://doi.org/10.1080/09638288.2019.1651909

Bordin, E. S. (1979). The generalizability of the psychoanalytic concept of the working alliance. Psychotherapy: Theory, research \& practice, 16(3), 252. DOI: https://doi.org/10.1037/h0085885

Bright, F. A., Kayes, N. M., Cummins, C., Worrall, L. M., \& McPherson, K. M. (2017). Coconstructing engagement in stroke rehabilitation: a qualitative study exploring how practitioner engagement can influence patient engagement. Clinical rehabilitation, 31(10), 1396-1405. DOI: https://doi.org/10.1177/0269215517694678 
RUNNING HEAD: Predictors of the Alliance

Bright, F. A., Kayes, N. M., Worrall, L., \& McPherson, K. M. (2015). A conceptual review of engagement in healthcare and rehabilitation. Disability and rehabilitation, 37(8), 643-654. DOI: https://doi.org/10.3109/09638288.2014.933899

Burgess, P. W., \& Shallice, T. (1997). The Hayling and Brixton tests. Thurston, Suffolk: Thames Valley Test Company.

Byrne, C., Coetzer, R., \& Addy, K. (2017). Investigating the discrepancy between subjective and objective cognitive impairment following acquired brain injury: The role of psychological affect. NeuroRehabilitation, 41(2), 501-512. DOI:

Coetzer, B. R., Vaughan, F. L., Roberts, C. B., \& Rafal, R. (2003). The development of a holistic, community based neurorehabilitation service in a rural area. Journal of Cognitive Rehabilitation, 21(1), 4-15.

Coetzer, R. (2008). Holistic neuro-rehabilitation in the community: Is identity a key issue?. Neuropsychological Rehabilitation, 18(5-6), 766-783. DOI: https://doi.org/10.1080/09602010701860266

Coetzer, R., Roberts, C., Turnbull, O. H., \& Vaughan, F. L. (2018). Neuropsychoanalytically informed psychotherapy approaches to rehabilitation: The North Wales Brain Injury ServiceBangor University experience 1998-2018. Neuropsychoanalysis, 20(1), 3-13. DOI: https://doi.org/10.1080/15294145.2018.1478747

Colantonio, A., Ratcliff, G., Chase, S., Kelsey, S., Escobar, M., \& Vernich, L. (2004). Long term outcomes after moderate to severe traumatic brain injury. Disability and Rehabilitation, 26(5), 253-261. DOI: https://doi.org/10.1080/09638280310001639722

Comper, P., Bisschop, S. M., Carnide, N., \& Tricco, A. (2005). A systematic review of treatments for mild traumatic brain injury. Brain injury, 19(11), 863-880. 
RUNNING HEAD: Predictors of the Alliance

Couchman, G., McMahon, G., Kelly, A., \& Ponsford, J. (2014). A new kind of normal: qualitative accounts of multifamily group therapy for acquired brain injury. Neuropsychological rehabilitation, 24(6), 809-832. DOI: https://doi.org/10.1080/09602011.2014.912957

Crowe, T. P., \& Grenyer, B. F. (2008). Is therapist alliance or whole group cohesion more influential in group psychotherapy outcomes?. Clinical Psychology \& Psychotherapy, 15(4), 239-246. DOI: https://doi.org/10.1002/cpp.583

Cruwys, T., Haslam, S. A., Dingle, G. A., Haslam, C., \& Jetten, J. (2014). Depression and social identity: An integrative review. Personality and Social Psychology Review, 18(3), 215-238. DOI: https://doi.org/10.1177/1088868314523839

Dawkins, N., Cloherty, M. E., Gracey, F., \& Evans, J. J. (2006). The factor structure of the Hospital Anxiety and Depression Scale in acquired brain injury. Brain injury, 20(12), 1235-1239. DOI: https://doi.org/10.1080/02699050601076414

Delis, D. C., Kaplan, E., \& Kramer, J. H. (2001). Delis-Kaplan Executive function system: examiners manual. Psychological Corporation.

Department of Health. (2005) National service framework for long term conditions. London: Fact Department of Health.

Draper, K., Ponsford, J., \& Schönberger, M. (2007). Psychosocial and emotional outcomes 10 years following traumatic brain injury. The Journal of head trauma rehabilitation, 22(5), 278-287. DOI: 10.1097/01.HTR.0000290972.63753.a7

Draper, K., Ponsford, J., \& Schönberger, M. (2007). Psychosocial and emotional outcomes 10 years following traumatic brain injury. The Journal of head trauma rehabilitation, 22(5), 278-287. DOI: 10.1097/01.HTR.0000290972.63753.a7

Efron, B. (2003). Second thoughts on the bootstrap. Statistical Science, 18(2), 135-140. 
RUNNING HEAD: Predictors of the Alliance

Ergh, T. C., Rapport, L. J., Coleman, R. D., \& Hanks, R. A. (2002). Predictors of caregiver and family functioning following traumatic brain injury: Social support moderates caregiver distress. The Journal of head trauma rehabilitation, 17(2), 155-174.

Evans, C. C., Sherer, M., Nakase-Richardson, R., Mani, T., \& Irby Jr, J. W. (2008). Evaluation of an Interdisciplinary Team Intervention to Improve Therapeutic Alliance in Post-acute Brain Injury Rehabilitation. The Journal of head trauma rehabilitation, 23(5), 329-338. DOI: 10.1097/01.HTR.0000336845.06704.bc

Evans, N. J., \& Jarvis, P. A. (1986). The group attitude scale: A measure of attraction to group. Small Group Behavior, 17(2), 203-216. DOI: https://doi.org/10.1177/104649648601700205

Ferreira, P. H., Ferreira, M. L., Maher, C. G., Refshauge, K. M., Latimer, J., \& Adams, R. D. (2013). The therapeutic alliance between clinicians and patients predicts outcome in chronic low back pain. Physical therapy, 93(4), 470-478. DOI: https://doi.org/10.2522/ptj.20120137

Gainotti, G. (1993). Emotional and psychosocial problems after brain injury. Neuropsychological rehabilitation, 3(3), 259-277. DOI: https://doi.org/10.1080/09602019308401440

Gibbon, B. (2004). Service User Involvement: The impact of stroke and the meaning of rehabilitation (part 1) Service User Involvement: Key Contributors, Goal Setting and Discharge Home (part 2). JARNA, 7(2), 8-12.

Goldstein, K. (1965). The Organism. New York: Zone Books, 1995

Hall, A. M., Ferreira, P. H., Maher, C. G., Latimer, J., \& Ferreira, M. L. (2010). The influence of the therapist-patient relationship on treatment outcome in physical rehabilitation: a systematic review. Physical therapy, 90(8), 1099-1110. DOI: https://doi.org/10.2522/ptj.20090245

Henry, J. D., \& Crawford, J. R. (2004). A meta-analytic review of verbal fluency performance in patients with traumatic brain injury. Neuropsychology, 18(4), 621. DOI: http://dx.doi.org/10.1037/0894-4105.18.4.621 
RUNNING HEAD: Predictors of the Alliance

Hiott, D. W., \& Labbate, L. (2002). Anxiety disorders associated with traumatic brain injuries. NeuroRehabilitation, 17(4), 345-355. DOI:

Horvath, A. O., \& Greenberg, L. S. (1989). Development and validation of the Working Alliance Inventory. Journal of counseling psychology, 36(2), 223. DOI: https://doi.org/10.1037/00220167.36.2.223

Horvath, A. O., \& Luborsky, L. (1993). The role of the therapeutic alliance in psychotherapy. Journal of consulting and clinical psychology, 61(4), 561. DOI: https://doi.org/10.1037/0022-006X.61.4.561

Horvath, A. O., \& Symonds, B. D. (1991). Relation between working alliance and outcome in psychotherapy: A meta-analysis. Journal of counseling psychology, 38(2), 139. DOI: 10.1037/0022-0167.38.2.139

Jorge, R. E., Robinson, R. G., Moser, D., Tateno, A., Crespo-Facorro, B., \& Arndt, S. (2004). Major depression following traumatic brain injury. Archives of general psychiatry, 61(1), 42-50. DOI: $10.1001 / \operatorname{archpsyc} .61 .1 .42$

Judd, D., \& Wilson, S. L. (2005). Psychotherapy with brain injury survivors: An investigation of the challenges encountered by clinicians and their modifications to therapeutic practice. Brain Injury, 19(6), 437-449. DOI: https://doi.org/10.1080/02699050400010994

Klonoff, P. S., Lamb, D. G., \& Henderson, S. W. (2001). Outcomes from milieu-based neurorehabilitation at up to 11 years post-discharge. Brain Injury, 15(5), 413-428. DOI: https://doi.org/10.1080/02699050116744

Kreutzer, J. S., Seel, R. T., \& Gourley, E. (2001). The prevalence and symptom rates of depression after traumatic brain injury: a comprehensive examination. Brain injury, 15(7), 563-576. DOI: https://doi.org/10.1080/02699050116884 
RUNNING HEAD: Predictors of the Alliance

Krug, E., \& Cieza, A. (2019). Strengthening health systems to provide rehabilitation services. Neuropsychological rehabilitation, 29(5), 672-674. DOI: https://doi.org/10.1080/09602011.2017.1319391

Lawton, M., Haddock, G., Conroy, P., \& Sage, K. (2016). Therapeutic alliances in stroke rehabilitation: A meta-ethnography. Archives of Physical Medicine and Rehabilitation, 97(11), 1979-1993. DOI: https://doi.org/10.1016/j.apmr.2016.03.031

Leclercq, M., Deloche, G., and Rousseaux, M. (2002). “Attentional complaints evoked by traumatic brain injured and stroke patients: frequency and importancy," in Applied Neuropsychology of Attention: Theory, Diagnosis and Rehabilitation, eds M. Leclercq and P. Zimmermann (London: Psychology Press), 89-109

Lenze, E. J., Munin, M. C., Quear, T., Dew, M. A., Rogers, J. C., Begley, A. E., \& Reynolds III, C. F. (2004). Significance of poor patient participation in physical and occupational therapy for functional outcome and length of stay. Archives of physical medicine and rehabilitation, 85(10), 1599-1601. DOI: https://doi.org/10.1016/j.apmr.2004.03.027

Lequerica, A. H., \& Kortte, K. (2010). Therapeutic engagement: a proposed model of engagement in medical rehabilitation. American journal of physical medicine \& rehabilitation, 89(5), 415422. DOI: 10.1097/PHM.0b013e3181d8ceb2

Levack, W. M., Kayes, N. M., \& Fadyl, J. K. (2010). Experience of recovery and outcome following traumatic brain injury: a metasynthesis of qualitative research. Disability and rehabilitation, 32(12), 986-999. DOI: https://doi.org/10.3109/09638281003775394

Lundqvist, A., Linnros, H., Orlenius, H., \& Samuelsson, K. (2010). Improved self-awareness and coping strategies for patients with acquired brain injury—A group therapy programme. Brain injury, 24(6), 823-832.DOI: https://doi.org/10.3109/02699051003724986 
RUNNING HEAD: Predictors of the Alliance

Lustig, D. C., Strauser, D. R., Weems, G. H., Donnell, C. M., \& Smith, L. D. (2003). Traumatic brain injury and rehabilitation outcomes: does the working alliance make a difference?. Journal of Applied Rehabilitation Counseling, 34(4), 30. Retrieved from https://search.proquest.com/docview/216473171?accountid=14874

Maddux, J. E., \& Meier, L. J. (1995). Self-efficacy and depression. In Self-Efficacy, adaptation, and adjustment (pp. 143-169). Springer, Boston, MA.

Martin, D. J., Garske, J. P., \& Davis, M. K. (2000). Relation of the therapeutic alliance with outcome and other variables: a meta-analytic review. Journal of consulting and clinical psychology, 68(3), 438. DOI: 10.1037/0022-006X.68.3.438

Marziali, E., Munroe-Blum, H., \& McCleary, L. (1997). The contribution of group cohesion and group alliance to the outcome of group psychotherapy. International Journal of Group Psychotherapy, 47(4), 475-497. DOI: https://doi.org/10.1080/00207284.1997.11490846

Mcallister, T. W., Flashman, L. A., Sparling, M. B., \& Saykin, A. J. (2004). Working memory deficits after traumatic brain injury: catecholaminergic mechanisms and prospects for treatment—a review. Brain Injury, 18(4), 331-350. DOI:

https://doi.org/10.1080/02699050310001617370

McCormack, B., Karlsson, B., Dewing, J., \& Lerdal, A. (2010). Exploring person-centredness: a qualitative meta-synthesis of four studies. Scandinavian Journal of Caring Sciences, 24(3), 620-634. DOI: https://doi.org/10.1111/j.1471-6712.2010.00814.x

Millis, S. R., Rosenthal, M., Novack, T. A., Sherer, M., Nick, T. G., Kreutzer, J. S., ... \& Ricker, J. H. (2001). Long-term neuropsychological outcome after traumatic brain injury. The Journal of head trauma rehabilitation, 16(4), 343-355. 
RUNNING HEAD: Predictors of the Alliance

Moore, P. A., Salas, C. E., Dockree, S., \& Turnbull, O. H. (2017). Observations on working psychoanalytically with a profoundly amnesic patient. Frontiers in psychology, 8,1418 . DOI: https://doi.org/10.3389/fpsyg.2017.01418

Morton, M. V., \& Wehman, P. (1995). Psychosocial and emotional sequelae of individuals with traumatic brain injury: a literature review and recommendations. Brain injury, $9(1), 81-92$. DOI: https://doi.org/10.3109/02699059509004574

Muscara, F., Catroppa, C., \& Anderson, V. (2008). Social problem-solving skills as a mediator between executive function and long-term social outcome following paediatric traumatic brain injury. Journal of neuropsychology, 2(2), 445-461.DOI: https://doi.org/10.1348/174866407X250820

Odhuba, R. A., Van den Broek, M. D., \& Johns, L. C. (2005). Ecological validity of measures of executive functioning. British Journal of Clinical Psychology, 44(2), 269-278. DOI: https://doi.org/10.1348/014466505X29431

Ownsworth, T., \& Fleming, J. (2005). The relative importance of metacognitive skills, emotional status, and executive function in psychosocial adjustment following acquired brain injury. The Journal of head trauma rehabilitation, 20(4), 315-332.

Peckham, A. D., McHugh, R. K., \& Otto, M. W. (2010). A meta-analysis of the magnitude of biased attention in depression. Depression and anxiety, 27(12), 1135-1142. DOI: https://doi.org/10.1002/da.20755

Peiris, C. L., Taylor, N. F., \& Shields, N. (2012). Patients value patient-therapist interactions more than the amount or content of therapy during inpatient rehabilitation: a qualitative study. Journal of Physiotherapy, 58(4), 261-268. DOI: https://doi.org/10.1016/S18369553(12)70128-5 
RUNNING HEAD: Predictors of the Alliance

Ponsford, J., Draper, K., \& Schönberger, M. (2008). Functional outcome 10 years after traumatic brain injury: its relationship with demographic, injury severity, and cognitive and emotional status. Journal of the International Neuropsychological Society, 14(2), 233-242. DOI: https://doi.org/10.1017/S1355617708080272

Ponsford, J., Draper, K., \& Schönberger, M. (2008). Functional outcome 10 years after traumatic brain injury: its relationship with demographic, injury severity, and cognitive and emotional status. Journal of the International Neuropsychological Society, 14(2), 233-242.

DOI: https://doi.org/10.1017/S1355617708080272

Prigatano, G. P. (2005). Disturbances of self-awareness and rehabilitation of patients with traumatic brain injury: a 20-year perspective. The Journal of head trauma rehabilitation, 20(1), 19-29.

Ramanathan-Elion, D. M., McWhorter, J. W., Wegener, S. T., \& Bechtold, K. T. (2016). The role of psychological facilitators and barriers to therapeutic engagement in acute, inpatient rehabilitation. Rehabilitation psychology, 61(3), 277. DOI: http://dx.doi.org/10.1037/rep0000095

Riley, G. A., Brennan, A. J., \& Powell, T. (2004). Threat appraisal and avoidance after traumatic brain injury: why and how often are activities avoided?. Brain Injury, 18(9), 871-888. DOI: https://doi.org/10.1080/02699050410001671829

Rohde, A., Townley-O'Neill, K., Trendall, K., Worrall, L., \& Cornwell, P. (2012). A comparison of client and therapist goals for people with aphasia: A qualitative exploratory study. Aphasiology, 26(10), 1298-1315. DOI: https://doi.org/10.1080/02687038.2012.706799

Rosti-Otajärvi, E., Mäntynen, A., Koivisto, K., Huhtala, H., \& Hämäläinen, P. (2014). Predictors and impact of the working alliance in the neuropsychological rehabilitation of patients with 
RUNNING HEAD: Predictors of the Alliance

multiple sclerosis. Journal of the neurological sciences, 338(1-2), 156-161. DOI:

https://doi.org/10.1016/j.jns.2013.12.039

Salas, C. E. (2012). Surviving catastrophic reaction after brain injury: the use of self-regulation and self-other regulation. Neuropsychoanalysis, 14(1), 77-92. DOI:

https://doi.org/10.1080/15294145.2012.10773691

Salas, C. E., Casassus, M., Rowlands, L., Pimm, S., \& Flanagan, D. A. (2018). "Relating through sameness": a qualitative study of friendship and social isolation in chronic traumatic brain injury. Neuropsychological rehabilitation, 28(7), 1161-1178. DOI:

https://doi.org/10.1080/09602011.2016.1247730

Salas, C. E., Casassus, M., Rowlands, L., Pimm, S., \& Flanagan, D. A. (2018). "Relating through sameness": a qualitative study of friendship and social isolation in chronic traumatic brain injury. Neuropsychological rehabilitation, 28(7), 1161-1178. DOI:

https://doi.org/10.1080/09602011.2016.1247730

Salibián-Barrera, M., Van Aelst, S., \& Willems, G. (2008). Fast and robust bootstrap. Statistical Methods and Applications, 17(1), 41-71.

Schönberger, M., \& Ponsford, J. (2010). The factor structure of the Hospital Anxiety and Depression Scale in individuals with traumatic brain injury. Psychiatry research, 179(3), 342-349. DOI: https://doi.org/10.1016/j.psychres.2009.07.003

Schönberger, M., Humle, F., \& Teasdale, T. W. (2006b). Subjective outcome of brain injury rehabilitation in relation to the therapeutic working alliance, client compliance and awareness. Brain Injury, 20(12), 1271-1282. DOI:

https://doi.org/10.1080/02699050601049395 
RUNNING HEAD: Predictors of the Alliance

Schönberger, M., Humle, F., \& Teasdale, T. W. (2006c). The development of the therapeutic working alliance, patients' awareness and their compliance during the process of brain injury rehabilitation. Brain Injury, 20(4), 445-454. DOI:

https://doi.org/10.1080/02699050600664772

Schönberger, M., Humle, F., \& Teasdale, T. W. (2007). The relationship between clients' cognitive functioning and the therapeutic working alliance in post-acute brain injury rehabilitation. Brain Injury, 21(8), 825-836. DOI:

https://doi.org/10.1080/02699050701499433

Schönberger, M., Humle, F., Zeeman, P., \& Teasdale, T. W. (2006a). Working alliance and patient compliance in brain injury rehabilitation and their relation to psychosocial outcome. Neuropsychological Rehabilitation, 16(3), 298-314. DOI: https://doi.org/10.1080/09602010500176476

Sherer, M., Evans, C. C., Leverenz, J., Stouter, J., Irby Jr, J. W., Eun Lee, J., \& Yablon, S. A. (2007). Therapeutic alliance in post-acute brain injury rehabilitation: predictors of strength of alliance and impact of alliance on outcome. Brain Injury, 21(7), 663-672. DOI: https://doi.org/10.1080/02699050701481589

Siegert, R. J., \& Taylor, W. J. (2004). Theoretical aspects of goal-setting and motivation in rehabilitation. Disability and rehabilitation, 26(1), 1-8. DOI: https://doi.org/10.1080/09638280410001644932

Skidmore, E. R., Whyte, E. M., Holm, M. B., Becker, J. T., Butters, M. A., Dew, M. A., ... \& Lenze, E. J. (2010). Cognitive and affective predictors of rehabilitation participation after stroke. Archives of physical medicine and rehabilitation, 91(2), 203-207. DOI: https://doi.org/10.1016/j.apmr.2009.10.026 
RUNNING HEAD: Predictors of the Alliance

Smith, B. (2013). Depression and motivation. Phenomenology and the Cognitive Sciences, 12(4), 615-635. DOI: 10.1007/s11097-012-9264-0

Stagg, K., Douglas, J., \& Iacono, T. (2017). A scoping review of the working alliance in acquired brain injury rehabilitation. Disability and rehabilitation, 41(4), 489-497. DOI: https://doi.org/10.1080/09638288.2017.1396366

Tracey, T. J., \& Kokotovic, A. M. (1989). Factor structure of the working alliance inventory. Psychological Assessment: A journal of consulting and clinical psychology, 1(3), 207. DOI: doi:10.1037/1040-3590.1.3.207

Tyerman, A., \& Hucker, R. (2016). Community Brain Injury Rehabilitation Services Benchmarking Exercise. Buckinghamshire Healthcare NHS Trust: United Kingdom

Watkins, P. C., Vache, K., \& Verney, S. P. Muller. S., \& Mathews, A.(1996). Unconscious moodcongruent memory bias in depression. Journal of Abnormal Psychology, 105(3), 4.

Wechsler, D. (2008). Wechsler Adult Intelligence Scale-Fourth Edition (WAIS-IV). San Antonio, TX: The Psychological Corporation.

Wechsler, D. (2009). Wechsler Memory Scale-Fourth Edition, San Antonio,, TX: Pearson.

Weddell, R., Oddy, M., \& Jenkins, D. (1980). Social adjustment after rehabilitation: a two year follow-up of patients with severe head injury. Psychological Medicine, 10(2), 257-263. DOI: https://doi.org/10.1017/S0033291700044019

Whelan-Goodinson, R., Ponsford, J. L., Schönberger, M., \& Johnston, L. (2010). Predictors of psychiatric disorders following traumatic brain injury. The Journal of head trauma rehabilitation, 25(5), 320-329. DOI: 10.1097/HTR.0b013e3181c8f8e7

World Health Organization. (2014). WHO methods and data sources for country-level causes of death 2000-2012. Geneva, Switzerland: WHO. 
RUNNING HEAD: Predictors of the Alliance

Yalom, I. D., \& Rand, K. (1966). Compatibility and cohesiveness in therapy groups. Archives of General Psychiatry, 15(3), 267-275. DOI: 10.1001/archpsyc.1966.01730150043007

Zelencich, L., Kazantzis, N., Wong, D., McKenzie, D., Downing, M., \& Ponsford, J. (2019).

Predictors of working alliance in cognitive behaviour therapy adapted for traumatic brain injury. Neuropsychological rehabilitation, 1-19. DOI:

https://doi.org/10.1080/09602011.2019.1600554

Zigmond, A. S., \& Snaith, R. P. (1983). The hospital anxiety and depression scale. Acta psychiatrica scandinavica, 67(6), 361-370. DOI: https://doi.org/10.1111/j.1600-0447.1983.tb09716.x 
RUNNING HEAD: Predictors of the Alliance

Table 1. Descriptive Statistics

\begin{tabular}{|c|c|c|c|c|}
\hline Variable & $\mathbf{M}$ & SD & Mdn & Range \\
\hline Age & 52.34 & 11.98 & 54.00 & $26-86$ \\
\hline Education & 13.57 & 2.14 & 13.00 & $10-20$ \\
\hline Anxiety (HADS) & 11.20 & 3.46 & 11.00 & $4-18$ \\
\hline $\begin{array}{l}\text { Depression } \\
\text { (HADS) }\end{array}$ & 9.14 & 3.79 & 8.50 & $2-16$ \\
\hline $\begin{array}{l}\text { Inhibition } \\
\text { (Hayling task) }\end{array}$ & 4.70 & 1.83 & 5.00 & $1-8$ \\
\hline $\begin{array}{l}\text { Verbal fluency } \\
\text { (D-KEFS) }\end{array}$ & 6.82 & 3.62 & 6.00 & $1-19$ \\
\hline $\begin{array}{l}\text { Working memory } \\
\text { (Digits WAIS) }\end{array}$ & 7.18 & 2.62 & 7.50 & $3-13$ \\
\hline $\begin{array}{l}\text { Logical memory } 1 \\
\text { (WMS) }\end{array}$ & 6.18 & 2.81 & 5.00 & $1-11$ \\
\hline $\begin{array}{l}\text { Logical memory } 2 \\
\text { (WMS) }\end{array}$ & 5.68 & 2.84 & 6.00 & $1-11$ \\
\hline Patient TA ratings & 73.30 & 9.36 & 74.50 & $52-84$ \\
\hline $\begin{array}{l}\text { Therapist alliance } \\
\text { ratings }\end{array}$ & 67.45 & 7.63 & 69.00 & $46-82$ \\
\hline $\begin{array}{l}\text { Group attitude } \\
\text { ratings }\end{array}$ & 156.05 & 16.27 & 157.50 & $120-180$ \\
\hline Engagement & 3.41 & 1.25 & 4.00 & $1-5$ \\
\hline
\end{tabular}


RUNNING HEAD: Predictors of the Alliance

Table 2. Robust Multiple Linear Regression results for the patient therapeutic alliance ratings (outcome variable)

\begin{tabular}{|c|c|c|c|c|c|c|}
\hline Model & $\mathrm{R}^{2}$ & $F$ & $\begin{array}{l}p \\
\text { (sig.) }\end{array}$ & $\begin{array}{l}\beta \text { coefficients } \\
\text { (bootstrapped) }\end{array}$ & $p$ (sig.) & $95 \%$ CIs \\
\hline $\begin{array}{l}\text { Demographic } \\
\text { predictor } \\
\text { variables }\end{array}$ & .05 & 2.28 & .321 & & & \\
\hline Age & & & & -0.01 & .475 & $-0.25-0.24$ \\
\hline Education & & & & 1.07 & .083 & $-0.63-2.49$ \\
\hline $\begin{array}{l}\text { Cognitive } \\
\text { predictor } \\
\text { variables }\end{array}$ & .14 & 5.96 & .310 & & & \\
\hline Inhibition & & & & -0.83 & .174 & $-2.59-1.05$ \\
\hline Working memory & & & & -0.42 & .313 & $-1.82-1.17$ \\
\hline Verbal fluency & & & & -0.44 & .167 & $-1.38-0.56$ \\
\hline Memory 1 & & & & -1.58 & .153 & $-3.91-1.55$ \\
\hline Memory 2 & & & & 1.77 & .144 & $-1.44-4.30$ \\
\hline $\begin{array}{l}\text { Emotional } \\
\text { predictor } \\
\text { variables }\end{array}$ & .06 & 2.42 & .300 & & & \\
\hline Anxiety & & & & -0.02 & .501 & $-1.01-1.04$ \\
\hline Depression & & & & -0.65 & .076 & $-1.63-0.23$ \\
\hline
\end{tabular}

Data is presented for three regression models containing 1) demographic predictor variables,

2) cognitive predictor variables, and 3) emotional predictor variables. 
RUNNING HEAD: Predictors of the Alliance

Table 3. Robust Multiple Linear Regression results for the Facilitator therapeutic alliance ratings (outcome variable)

\begin{tabular}{|c|c|c|c|c|c|c|}
\hline Model & $\mathrm{R}^{2}$ & $F$ & $p$ (sig.) & $\begin{array}{l}\beta \text { coefficients } \\
\text { (bootstrapped) }\end{array}$ & $p$ (sig.) & $95 \%$ CIs \\
\hline $\begin{array}{l}\text { Demographic } \\
\text { predictor } \\
\text { variables }\end{array}$ & .00 & 0.17 & .921 & & & \\
\hline Age & & & & -0.02 & .413 & $-0.19-0.22$ \\
\hline Education & & & & 0.24 & .381 & $-0.09-1.38$ \\
\hline $\begin{array}{l}\text { Cognitive } \\
\text { predictor } \\
\text { variables }\end{array}$ & .11 & 4.16 & .526 & & & \\
\hline Inhibition & & & & 0.22 & .442 & $-1.18-1.47$ \\
\hline Working memory & & & & -0.76 & .074 & $-1.29-0.37$ \\
\hline Verbal fluency & & & & -0.27 & .261 & $-0.27-0.64$ \\
\hline Memory 1 & & & & -0.53 & .285 & $-0.53-1.39$ \\
\hline Memory 2 & & & & 0.58 & .284 & $0.58-2.24$ \\
\hline $\begin{array}{l}\text { Emotional } \\
\text { predictor } \\
\text { variables } \\
\end{array}$ & .16 & 17.11 & $<.001 * *$ & & & \\
\hline Anxiety & & & & 0.24 & .176 & $0.24-0.82$ \\
\hline Depression & & & & -0.83 & $.002 *$ & $-0.83--0.33$ \\
\hline
\end{tabular}

Data is presented for three regression models containing 1) demographic predictor variables,

2) cognitive predictor variables, and 3) emotional predictor variables. 
RUNNING HEAD: Predictors of the Alliance

Table 4. Robust Multiple Linear Regression results for patients' scores on the Group Attitude Scale (outcome variable)

\begin{tabular}{|c|c|c|c|c|c|c|}
\hline Model & $\mathrm{R}^{2}$ & $F$ & $p$ (sig.) & $\begin{array}{l}\beta \text { coefficients } \\
\text { (bootstrapped) }\end{array}$ & $p$ (sig.) & $95 \%$ CIs \\
\hline $\begin{array}{l}\text { Demographic } \\
\text { predictor } \\
\text { variables }\end{array}$ & .03 & 2.78 & .249 & & & \\
\hline Age & & & & 0.26 & .269 & $-0.50-0.26$ \\
\hline Education & & & & 1.43 & .061 & $-0.65-3.21$ \\
\hline $\begin{array}{l}\text { Cognitive } \\
\text { predictor } \\
\text { variables }\end{array}$ & .11 & 5.66 & .340 & & & \\
\hline Inhibition & & & & -0.03 & .425 & $-4.40-3.57$ \\
\hline Working memory & & & & 0.27 & .456 & $-2.79-4.30$ \\
\hline Verbal fluency & & & & -1.57 & $.049 *$ & $-3.25-0.33$ \\
\hline Memory 1 & & & & -0.44 & .428 & $-5.16-5.00$ \\
\hline Memory 2 & & & & 1.31 & .344 & $-5.34-6.93$ \\
\hline $\begin{array}{l}\text { Emotional } \\
\text { predictor } \\
\text { variables }\end{array}$ & .14 & 9.48 & $.008^{*}$ & & & \\
\hline Anxiety & & & & -0.06 & .515 & $-1.14-1.31$ \\
\hline Depression & & & & -1.61 & $.006^{*}$ & $-2.76--0.54$ \\
\hline
\end{tabular}

Data is presented for three regression models containing 1) demographic predictor variables,

2) cognitive predictor variables, and 3) emotional predictor variables. 
RUNNING HEAD: Predictors of the Alliance

Table 5. Robust Multiple Linear Regression results for patient engagement (outcome variable)

\begin{tabular}{|c|c|c|c|c|c|c|}
\hline Model & $\mathrm{R}^{2}$ & $F$ & $p$ (sig.) & $\begin{array}{l}\beta \text { coefficients } \\
\text { (bootstrapped) }\end{array}$ & $p$ (sig.) & $95 \%$ CIs \\
\hline $\begin{array}{l}\text { Demographic } \\
\text { predictor variables }\end{array}$ & .14 & 7.84 & $.020^{*}$ & & & \\
\hline Age & & & & -0.02 & .189 & $-0.05-0.02$ \\
\hline Education & & & & 0.22 & $.005^{*}$ & $0.06-0.39$ \\
\hline $\begin{array}{l}\text { Cognitive } \\
\text { predictor variables }\end{array}$ & .19 & 13.49 & $.019^{*}$ & & & \\
\hline Inhibition & & & & -0.11 & .127 & $1.42-4.36$ \\
\hline Working memory & & & & 0.18 & $.018^{*}$ & $0.02-0.33$ \\
\hline Verbal fluency & & & & -0.07 & .121 & $-0.20-0.05$ \\
\hline Memory 1 & & & & 0.29 & $.033^{*}$ & $-0.01-0.49$ \\
\hline Memory 2 & & & & -0.26 & $.037 *$ & $-0.48-0.03$ \\
\hline $\begin{array}{l}\text { Emotional } \\
\text { predictor variables }\end{array}$ & .02 & 1.00 & .610 & & & \\
\hline Anxiety & & & & 0.04 & .302 & $-0.09-0.16$ \\
\hline Depression & & & & -0.04 & .196 & $-0.16-0.06$ \\
\hline $\begin{array}{l}\text { Alliance and group } \\
\text { attitude predictor } \\
\text { variables }\end{array}$ & .21 & 5.90 & .116 & & & \\
\hline $\begin{array}{r}\text { Patient alliance } \\
\text { ratings }\end{array}$ & & & & 0.01 & .407 & $-0.07-0.08$ \\
\hline $\begin{array}{r}\text { Facilitator alliance } \\
\text { ratings }\end{array}$ & & & & 0.05 & .108 & $-0.03-0.12$ \\
\hline $\begin{array}{r}\text { Group attitude } \\
\text { scores }\end{array}$ & & & & 0.01 & .206 & $-0.02-0.04$ \\
\hline
\end{tabular}

Data is presented for three regression models containing 1) demographic predictor variables,

2) cognitive predictor variables, 3) emotional predictor variables, and 4) therapeutic alliance and group attitude 
RUNNING HEAD: Predictors of the Alliance

Figure 1.

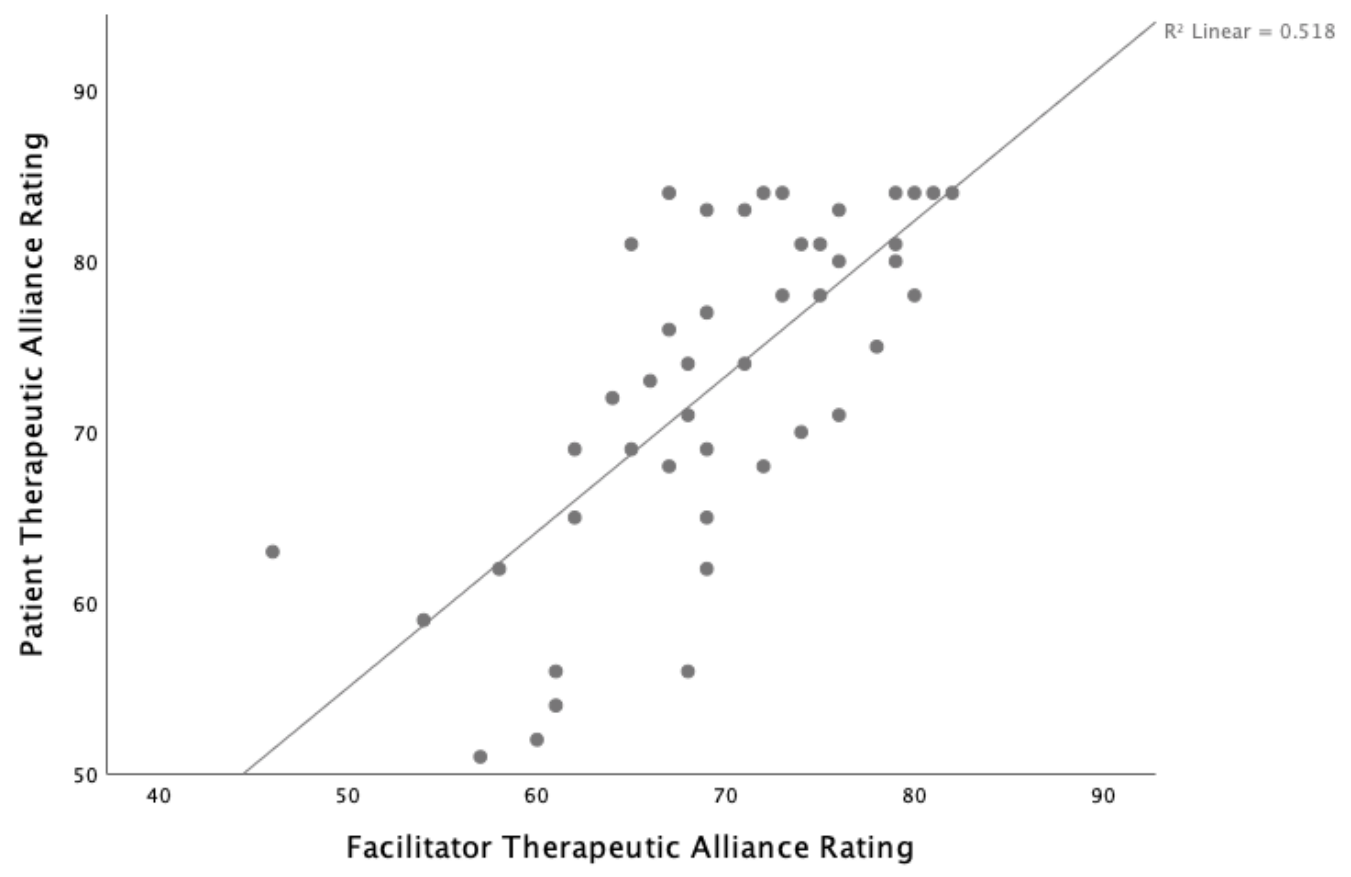

Figure 1. Scatter plot demonstrating the correlation between patient and facilitator perceptions of the strength of the alliance. 